\title{
PRÁTICAS SOCIAIS DE LEITURA E ESCRITA DE ALUNOS NA EDUCAÇÃO DE JOVENS E ADULTOS E SUAS IMPLICAÇÕES NO UNIVERSO DA CULTURA LETRADA
}

\section{Social practices of reading and writing of students of youth and adult education and their implications in the universe of culture letrada}

Aliny Cardoso dos Santos ${ }^{1}$

RESUMO: O objetivo do presente estudo é analisar como as atividades propostas em sala de aula de uma turma de $8^{\circ}$ ano da Educação de Jovens e Adultos (EJA) relacionam-se ao universo dos alunos fora da escola. Para isso, temos como problema de pesquisa, o seguinte questionamento: Como as atividades propostas estão relacionadas ao universo dos alunos fora do ambiente escolar? Entendemos que a perspectiva de letramento adotada no contexto escolar de EJA seja decisivo para a aprendizagem da leitura e da escrita e para as implicações na vida desses alunos. Utilizamos como procedimentos metodológicos, a pesquisa qualitativa, com abordagem etnográfica, realizada por meio de uma pesquisa de campo. Os dados coletados para análise foram contextos reais de sala de aula, registrados a partir da observação participante, diário de campo e questionários. Como fundamentação teórica, utilizamos os postulados da teoria do letramento social, de Street (1984; 1993; 1995; 2003; 2014), seguido das leituras de Antunes (2003), Ferrarezi Júnior (2014), Ferreiro (2011), Freire (1995), Jardilino; Araújo (2014), Kleiman (1995), Lopes (2006), Soares (2010), entre outros. A partir dos dados coletados foi possível constatar que, mesmo estando inseridos numa cultura letrada, esses alunos ainda vivem à margem dela porque essa participação não é efetiva. Não há a participação plena, enquanto cidadãos em todos os setores artísticos e culturais, dado visível quando eles afirmam não frequentarem o teatro, cinema e museus.

Palavras-chave: Letramento. Leitura. Escrita. Cultura letrada.

ABSTRACT: The objective of the present study is to analyze how the activities proposed in the classroom of an 8th grade class of Youth and Adult Education (EJA) relate to the universe of students out of school. For this, we have as a research problem, the following question: How are the proposed activities related to the universe of students outside the school environment? We understand that the perspective of literacy adopted in the school context of EJA is decisive for the learning of reading and writing and for the implications in the life of these students. We used as methodological procedures, the qualitative research, with ethnographic

\footnotetext{
${ }^{1}$ Graduada em Letras - Português (UESPI). Mestra em Letras - Estudos da Linguagem pela Universidade Federal do Piauí (UFPI). Professora da Secretaria de Educação do Maranhão (SEDUC-MA) e pesquisadora do grupo de pesquisa Linguagem, Escola e Sociedade (LES/UFPI). E-mail: fcorenatolima@hotmail.com
} 
approach, accomplished through a field research. The data collected for analysis were real classroom contexts, recorded from participant observation, field diary and questionnaires. As a theoretical foundation, we used the postulates of the social literacy theory of Street $(1984 ; 1993 ; 1995 ; 2003 ; 2014)$, followed by the readings of Antunes (2003), Ferrarezi Júnior (2014), Ferreiro (2011), Freire (1995), Jardilino; Araújo (2014), Kleiman (1995), Lopes (2006), Soares (2010), among others. Based on the collected data, it was possible to verify that, even though they are inserted in a literate culture, these students still live on the margin because this participation is not effective. There is no full participation, as citizens in all artistic and cultural sectors, made visible when they claim not to attend the theater, cinema and museums.

Keywords: Literacy. Reading. Writing. Literary culture.

\section{CONSIDERAÇÕES INICIAIS}

A história da educação brasileira tem passado por variadas modificações, no que diz respeito às suas diversas modalidades e segmentos. No que diz respeito à Educação de Jovens e Adultos (EJA), não foi diferente. Isso se deve ao fato de que essa modalidade de ensino necessita de uma atenção específica, principalmente com relação ao conhecimento sobre a clientela que pretende atender.

Quanto às verdadeiras necessidades dos alunos dessa modalidade de ensino, atentamos para o fato de que, mais do que aprender a ler e a escrever, é importante que esses sujeitos compreendam efetivamente aquilo que leem e que façam uso da escrita, enquanto tecnologia no mundo letrado, tendo em vista que, embora participem de algumas práticas de letramento, as suas habilidades ainda são bastante limitadas, em meio às demandas do mundo contemporâneo.

Por isso, a motivação para realizar este estudo partiu das inquietações de observarmos como acontecem as atividades de leitura e escrita em turmas de EJA e que contribuições essas atividades têm oferecido ao sucesso escolar. Em experiências de pesquisa vivenciadas anteriormente (SANTOS, 2016), notamos que a essa modalidade de ensino não é conferida a devida importância.

Dessa maneira, o modo como as práticas de leitura e escrita estão sendo encaminhadas na escola nos preocupa, visto que, professores e alunos estão imersos na cultura letrada, que exige cada vez mais um ensino de língua pautado na perspectiva social do letramento. O ensino de leitura e escrita desvinculado do contexto sociocultural pode afetar diretamente os sujeitos envolvidos no processo, 
uma vez que, a eles pode ser negado o direito de ter uma participação efetiva na sociedade, com o acesso às práticas sociais letradas.

Partindo de nossas inquietações, no que concerne à maneira como os professores conduzem as práticas de leitura e escrita na sala de aula, temos a seguinte questão norteadora: Como as atividades propostas estão relacionadas ao universo dos alunos fora do ambiente escolar? Para tanto, partimos incialmente, de uma fundamentação bibliográfica, sobre as concepções de leitura e escrita e as práticas de letramento, sobretudo, a partir de Street (1984; 1993; 1995; 2003; 2014).

Como este estudo trata de uma investigação acerca das práticas de leitura e escrita em EJA, entendemos que a pesquisa qualitativa, de abordagem etnográfica, é o melhor caminho a ser traçado para o processo de coleta, geração e análise dos dados obtidos. Isso porque, esse tipo de pesquisa permite o contato direto com o ambiente pesquisado. Esse entendimento de pesquisa na área dos letramentos, parte sobretudo, de Street (2003, p. 11), quando nos diz que:

\section{[...] a pesquisa de caráter etnográfico não sugere que as pessoas sejam simplesmente deixadas como estejam, com base no argumento relativista de que um tipo de letramento é tão bom quanto 0 outro. Mas também não sugere que as pessoas simplesmente devem "receber" o tipo de letramento formal e acadêmico conhecido pelos responsáveis pela determinação de políticas e que, de fato, muitas delas já terão rejeitado. "Fornecer" esse tipo de letramento formalizado não levará à atribuição de poder, não facilitará novos empregos e não gerará mobilidade social. (Grifos meus)}

Quanto ao cenário da pesquisa, ocorreu em uma turma de $8^{\circ}$ ano de uma escola pública municipal situada no Parque Anita Ferraz, Zona Leste de Teresina, Piauí. Nessa escola, funciona o Ensino Fundamental do $1^{\circ}$ ao $9^{\circ}$ ano nos turnos matutino, vespertino e noturno. Neste turno, funciona a modalidade de EJA, foco deste estudo. Na turma escolhida para a pesquisa, estão matriculados 15 alunos, no entanto, frequentam entre 6 e 10, apenas, os colaboradores do estudo.

A coleta dos dados aconteceu com base na observação participante na sala de aula, técnica em que ocorre o contato direto do pesquisador com o campo de pesquisa, a fim de obter informações acerca da realidade dos sujeitos envolvidos em seus contextos. Além da observação participante, realizamos entrevistas gravadas, partindo do fato de que, por meio desse instrumento, o pesquisador consegue captar informações contidas na fala dos entrevistados. 
Assim, os dados coletados encontram-se organizados na seção: "Atividades propostas em sala de aula e o universo que os alunos vivenciam fora da escola", na qual, a luz dos referenciais teóricos que embasaram a pesquisa, apresentamos algumas considerações críticas e reflexivas acerca dos achados da pesquisa. Desse modo, nossos resultados encaminham para uma reflexão sobre as implicações que as práticas de leitura e escrita têm na vida social dos sujeitos da EJA.

\section{CONCEPÇÕES DE LEITURA, ESCRITA E LETRAMENTO}

Durante muito tempo, a alfabetização esteve relacionada à aquisição da leitura e da escrita, considerando essas tecnologias como atividades mecânicas e repetitivas de decodificação da escrita. E a escola, desconsiderando o conhecimento de seus alunos, submetia-os a um ensino sem função social. Para Ferreiro (2011), o início da construção da língua escrita se dá bem antes do período escolar. Foi, então, a partir dos estudos dessa autora, com a nova perspectiva de aprendizagem da leitura e da escrita, surgida na década de 1980, que trouxe aos educadores, novos paradigmas em relação ao ensino e as novas práticas de alfabetização.

Desde esse período, o ensino de leitura e escrita vem percorrendo outros caminhos, que passaram a ser vistos com novas perspectivas de estudos linguísticos, dando prioridade aos usos da língua e às práticas sociais. Nessa perspectiva, o ensino da leitura e da escrita deve partir da realidade do aluno, considerando sua dimensão sociocultural, política e econômica, conforme destaca Freire (1995). E, a partir dessa nova perspectiva de aprendizagem da leitura e da escrita, é importante tornar o aluno parte do processo de conhecimento, fazendo-se necessário que esse sujeito seja muito além de um espectador.

A partir desses estudos, o processo de construção da língua escrita passou a ter um caráter mais complexo, pois envolve aprendizagens conceituais, em que os sujeitos constroem seu próprio conhecimento acerca da escrita (FERREIRO, 2011). Por isso, ao discutirmos o objeto da língua em qualquer modalidade de ensino, é importante repensarmos nossa maneira de ver esse ensino, a fim de que os alunos compreendam o real funcionamento da estrutura da língua e o seu uso na sociedade.

Ferrarezi Jr. (2014, p. 76) afirma que "a leitura no Brasil é um problema que extrapola os limites da escola, que cai na organização sociocultural do povo". 0 
autor comprova essa afirmação com os resultados apontados por uma recente pesquisa de instituição não governamental, em que ficou comprovado que $56 \%$ dos brasileiros nunca compraram um livro na vida. Além disso, cerca de $70 \%$ dos brasileiros leem menos que dois livros por ano e mais da metade não lê nada. São dados assustadores e, o pior disso tudo, é que esse dilema vai além dos muros da escola, retorna à escola, gerando problemas para toda a comunidade escolar e, consequentemente, contribuindo para o fracasso escolar.

Por esse motivo é tão importante que a escola lide com a leitura e com o ensinar a ler. Mas para que isso ocorra, o ensino de leitura e escrita não pode desvincular-se do contexto em que se encontram os sujeitos envolvidos, uma vez que para que a aprendizagem dessas práticas seja significativa, esses sujeitos precisam reconhecer-se como parte do processo de construção do conhecimento. Mais uma vez, destacamos o que Ferrarezi Jr. (2014, p. 80) afirma:

O ler escolar precisa ser muito e muito mais do que o decodificar letras, o conhecer as dificuldades ortográficas e saber como pronunciar frases que terminam com ponto de interrogação. O ler escolar precisa ser tudo isso e essencialmente precisa deixar de ser o ler escolar e se tornar o ler existencial (Grifo do autor).

Assim, o ler na escola deve ser encarado como o ler na e para a vida. Isso porque, enquanto a leitura na escola for somente "leitura da escola" e não for leitura da (e) para a vida, nossas crianças e jovens não gostarão de ler. Então, é primordial o conhecimento em torno das concepções de linguagem e as reflexões sobre elas, a fim de oferecermos um ensino relevante para os nossos alunos. Antunes (2003), no que diz respeito às atividades de ensino da leitura, afirma que, atualmente, essas atividades são centradas em habilidades mecânicas de decodificação da escrita, que desconsideram a interação verbal; além de serem atividades sem interesse e sem função, tendo em vista que aparecem desvinculadas dos diferentes usos sociais.

Nas palavras dela, "uma atividade de leitura puramente escolar, sem gosto, sem prazer, convertida em momento de treino, de avaliação ou em oportunidade para futuras 'cobranças"' (ANTUNES, 2003, p. 28). E ainda mais: uma atividade de leitura que se limita a recuperar elementos literais e explícitos presentes na superfície do texto é incapaz de provocar no aluno a compreensão das múltiplas funções sociais da leitura, como aponta essa autora. 
Dessa forma, na perspectiva de Ferrarezi Jr. (2014), a leitura deverá ser tratada como um tema presente e central nas aulas de língua. Para ele, é importante ensinar a ler na vida e para a vida, e ler junto. "Além disso, a leitura é, provavelmente, o mais eficiente meio de extirpar o silêncio da mente, de fazer soar um milhão de vozes dentro de nós até que, em meio a essas vozes todas, sejamos capazes de encontrar a nossa própria voz" (FERRAREZI JR., 2014, p. 82).

$E$, assim como a leitura, a escrita também é, na perspectiva da dimensão individual do letramento (a escrita enquanto tecnologia), um conjunto de habilidades linguísticas e psicológicas, diferentes daquelas exigidas pela leitura, como afirma Soares (2010). De acordo com a autora:

\begin{abstract}
Enquanto as habilidades de leitura estendem-se da habilidade de decodificar palavras escritas à capacidade de integrar informações provenientes de diferentes textos, as habilidades de escrita estendem-se da habilidade de registrar unidades de som até a capacidade de transmitir significado de forma adequada a um leitor potencial. (SOARES, 2010, p. 69)
\end{abstract}

Por isso, a autora defende que essas categorias não se opõem, complementam-se. A escrita por ser um processo de relacionar unidades de som a símbolos escritos, além de ser também, um processo de expressar ideias e organizar o pensamento. Essa afirmação pode ser comprovada nas palavras de Ferrarezi Jr. (2014, p. 83) quando ele enfatiza a importância da escola nesse processo: "O fato presente é que, embora a escrita seja uma tecnologia inescapável, nossas escolas não têm sido capazes de ensiná-la adequadamente". Podemos, então, dizer que a consequência disso é, dentre tantos motivos, à falta de tempo curricular, de condições de trabalho, de preparo adequado dos professores de língua, além da falta de envolvimento dos professores das demais disciplinas, como se todos os "erros de português" fossem de nossa responsabilidade.

É importante que à escrita seja dada a devida relevância, pois ela precisa ir muito além daquilo que a escola tem ensinado ultimamente. Enquanto não trabalharmos a escrita vinculada à vida, não será possível conscientizar o aluno para que ele valorize o que escreve e veja nela uma utilidade. $O$ aluno precisa ter contato com diferentes gêneros textuais, com finalidades comunicativas diversificadas, a fim de que essa habilidade passe a ser uma prática cotidiana na escola. Essa tarefa 
demanda tempo e muita prática, pois ensinar a escrever relaciona-se diretamente à formação das pessoas para que possam conviver efetivamente na cultura letrada.

Antunes (2003), também enfatiza que a prática de escrita se limita a uma escrita improvisada, sem planejamento e sem revisão, em que, o que conta é a tarefa de realizá-la. Ela propõe que a prática de escrita deve relacionar a linguagem e o mundo, a relação entre o autor e o leitor do texto, atribuindo-Ihe um valor interacional. E enquanto essa postura frente à leitura e à escrita não mudar, continuaremos formando analfabetos funcionais, pois os currículos escolares devem ser reconstruídos em razão das necessidades comunicativas reais dos alunos, revolucionando assim, o ensino de língua materna no país.

$\mathrm{Na}$ seção seguinte, a partir dos resultados da pesquisa de campo, discutiremos sobre a presença das práticas de leitura e escrita, no contexto da EJA, a partir dos que nos revelaram os alunos e os professores, sujeitos da pesquisa.

\section{ATIVIDADES PROPOSTAS EM SALA DE AULA E O UNIVERSO QUE OS ALUNOS VIVENCIAM FORA DA ESCOLA}

A seguir, analisaremos as principais situações em que os alunos da EJA, colaboradores da pesquisa, mais utilizam a leitura e a escrita no seu cotidiano. No questionário respondido por eles, havia um leque de situações em que eles deveriam assinalar as mais frequentes. Dentre essas situações constavam:

- Leitura de bula de remédios;

- Receitas

- Lista de compras;

- Leitura de correspondências;

- Ofertas de promoções em folhetos impressos;

- Escrever ou ler uma carta/bilhete;

- Realização de saques e depósitos em caixas eletrônicos;

- Verificação de data de validade em rótulos de produtos;

- Pegar ônibus;

- Leitura da Bíblia;

- Pesquisas diversas na internet.

A partir do que foi respondido, elaboramos o seguinte gráfico: 
GRÁFICO 1: Práticas de leitura e de escrita dos alunos

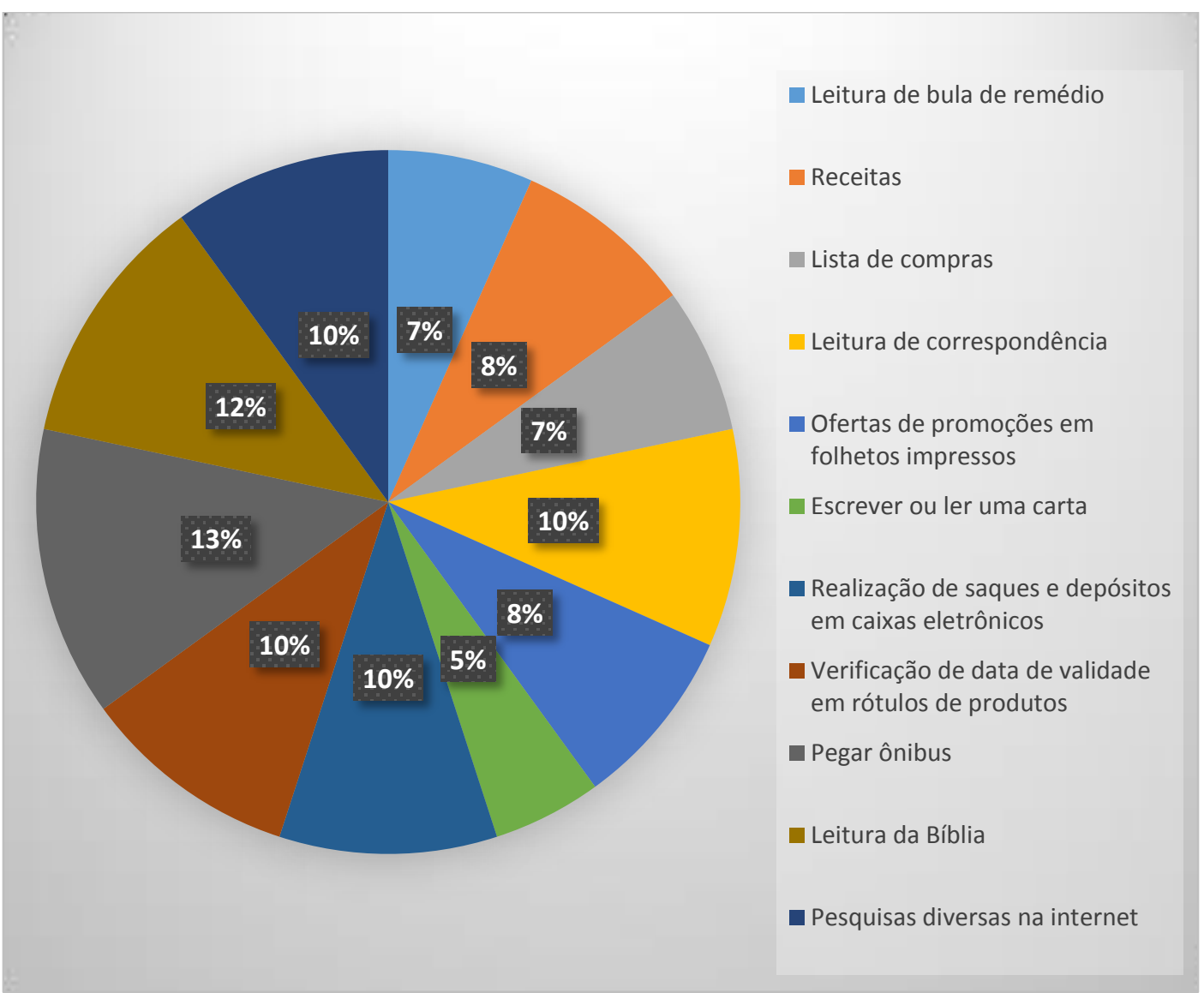

Fonte: Questionário aplicado aos colaboradores (2016)

Podemos observar, através do gráfico, que as práticas de leitura e de escrita desses alunos variam de acordo com o perfil de cada um. Por exemplo, escrever ou ler uma carta corresponde apenas a $5 \%$ das respostas, ou seja, significa dizer que, por se tratar de um gênero textual pouco utilizado, somente uma minoria afirmou fazer uso. Outro dado revelado, foi a utilização da leitura e da escrita em relação à bula de remédio, às receitas, à lista de compras e aos folhetos impressos. Os dados referentes à leitura da bula de remédio são representados por uma parcela dos colaboradores adultos, tendo em vista que, para eles, é um gênero textual bastante usado em razão de suas necessidades relativas à saúde ${ }^{2}$.

\footnotetext{
${ }^{2}$ A esse respeito, vale a pena a leitura do trabalho de Lima (2016), no qual, o autor, também, à luz dos estudos dos letramentos sociais, analisa as práticas de letramentos de pacientes (adultos) em contextos de consulta médica, identificando algumas cenas do cotidiano em que os sujeitos envolvem-se em diferentes circunstâncias de leitura - no sentido social e ideológico - dos gêneros bula de medicamentos e receita médica.
} 
Já referente às receitas, à lista de compras e aos folhetos impressos, com apenas $8 \%$ das respostas, é possível entendermos que, as receitas, assim como a lista de compras, estando mais ligadas ao mundo feminino, não fazem parte da rotina de um homem/rapaz, como foi demonstrado no questionário. Entretanto, surpreendentemente, desse percentual, 3 rapazes assinalaram fazer uso desses gêneros textuais em sua vida cotidiana. Além desses dados, representando também $8 \%$ das respostas, podemos enfatizar o contato desses colaboradores, com folhetos impressos. A predominância, dessa vez foi dos colaboradores mais jovens, uma vez que isso se justifique pelo fato de estarem mais envolvidos com as mídias e terem mais contato com o mundo da tecnologia.

Também, é possível notarmos, pelo gráfico, um percentual de respostas correspondente a $10 \%$. As práticas de leitura e de escrita que estão inscritas nesse percentual são: a realização de saques e depósitos em caixas eletrônicos; pesquisas diversas na internet; a leitura de correspondências e verificação da data de validade nos rótulos de produtos. Esses dados nos revelam o quanto os colaboradores estão cada vez mais se inserindo no universo letrado. Significa dizer que, dos mais jovens aos mais adultos, a leitura e a escrita permeiam a vida deles, desde situações simples, como ler uma correspondência e observar a data de validade de produtos; até uma situação mais complexa, como a realização de operações em caixas eletrônicos e pesquisas na internet.

As últimas situações analisadas com maior percentual de vivência são as de utilizar a leitura e a escrita para pegar ônibus e para ler a Bíblia. A primeira, por estar diretamente ligada à situação socioeconômica em que se encontram esses colaboradores, e, a outra, porque boa parte deles está ligada a alguma religião ou movimento religioso, que tenha a Bíblia como livro sagrado.

A partir de tais dados, podemos entender o quanto a leitura e a escrita estão intrinsecamente ligadas à vida dos colaboradores da pesquisa, confirmando o que destaca Soares (2010, p. 72), quando considera o letramento como o "conjunto de práticas sociais, ligadas à leitura e à escrita em que os indivíduos se envolvem em seu contexto social, à concepção de letramento". Por isso, envolve as mais diversas práticas de leitura e de escrita, nas mais variadas formas na sociedade.

Essa linha de investigação, que concebe a escrita como forma de interação social em que se observam os usos reais dela configurados nas práticas sociais faz parte dos estudos dos letramentos sociais, de Brian Street (1984; 1993; 1995; 2014). 
Acerca disso, Lopes (2006, p. 36) enfatiza que tal termo evidencia a natureza social da escrita "uma vez que se refere ao conjunto das práticas sociais em cujo processo estão envolvidas atividades de leitura e de escrita". Em outras palavras, essa autora destaca o fenômeno do letramento relacionado às atividades que envolvem a leitura e a escrita nas mais variadas práticas sociais.

Portanto, letrado não é apenas o indivíduo que faz uso formal da escrita, mas aquele que participa de maneira significativa de eventos de letramento, como saber o ônibus que deve pegar ou identificar o valor do dinheiro. O letramento pode ser visto por duas dimensões: como processo de alfabetização e relacionado às práticas sociais. E, através dos dados revelados no gráfico anterior, foi possível percebermos que os colaboradores da pesquisa apresentam níveis diversos de letramentos, do mais simples, como escrever ou ler uma carta; até o mais complexo, como realizar transações financeiras em caixas eletrônicos.

Dessa forma, podemos inferir a partir das diversas definições de leitura e escrita, que letramento é algo que extrapola a simples decodificação do código linguístico. Torna-se quase impossível se falar em letramento, nas práticas de leitura e escrita sem refazer uma associação lógica com a linguagem falada, dada a impossibilidade de se postular uma divisão rigorosa entre fala e escrita como atividades comunicativas (MAGALHÃES NETO, 2013, p. 23).

Por isso, o letramento vai muito além da alfabetização, principalmente pelo fato de que pessoas alfabetizadas não necessariamente adquirem competência para usar a leitura e a escrita e utilizá-las nas práticas sociais de leitura. Portanto, conceitos, definição e significação sobre o termo letramento, são conhecimentos que se encontram em construção. Diariamente, as pessoas fazem uso dessas práticas, que são decorrentes de sociedades letradas, desde uma lista de compras até as múltiplas pesquisas feitas na internet, como vimos no gráfico 01 .

A respeito disso, Kleiman (1995) também compartilha dessas premissas acerca do fenômeno do letramento. Para ela, o letramento extrapola o mundo da escrita, tal qual ele é concebido pelas instituições que se encarregam de introduzir formalmente os sujeitos no mundo da escrita. Assim, segundo a autora:

Pode-se afirmar que a escola, a mais importante das agências de letramento, preocupa-se, não com o letramento, prática social, mas com apenas um tipo de prática de letramento, a alfabetização, o processo de aquisição de códigos (alfabético, numérico), processo 
geralmente concebido em termos de uma competência individual necessária para o sucesso e promoção na escola. Já outras agências de letramento, como a família, a igreja, a rua como lugar de trabalho, mostram orientações de letramento muito diferentes (KLEIMAN, 1995, p. 20).

Assim, é possível percebermos que a concepção de letramento defendida por Kleiman (1995) vai muito mais além da aquisição e apreensão das habilidades de leitura e de escrita, uma vez que o letramento é relativo às condições reais às quais são submetidos os grupos sociais ao realizarem determinada prática social em que precisam utilizar a escrita. E, ao propormos no questionário que os alunos assinalassem as situações recorrentes em que utilizam a leitura e a escrita, foi com a finalidade de elencarmos operações/atividades, das mais simples às mais complexas, tentando traçar um perfil de aluno da EJA imerso nas práticas sociais a partir do fenômeno do letramento.

Além de demonstrar, por meio do gráfico, as situações cotidianas dos sujeitos em meio ao mundo da escrita, apresentaremos no gráfico a seguir, a rotina desses colaboradores e as principais atividades culturais de que eles fazem parte, com o intuito de compreendermos como estes alunos sentem-se em relação à sociedade letrada. Sugerimos que eles assinalassem dentre as alternativas, desde atividades simples como assistir TV; até ir ao Teatro, visitar museus etc.

GRÁFICO 2: Rotina das práticas de leitura e escrita dos alunos

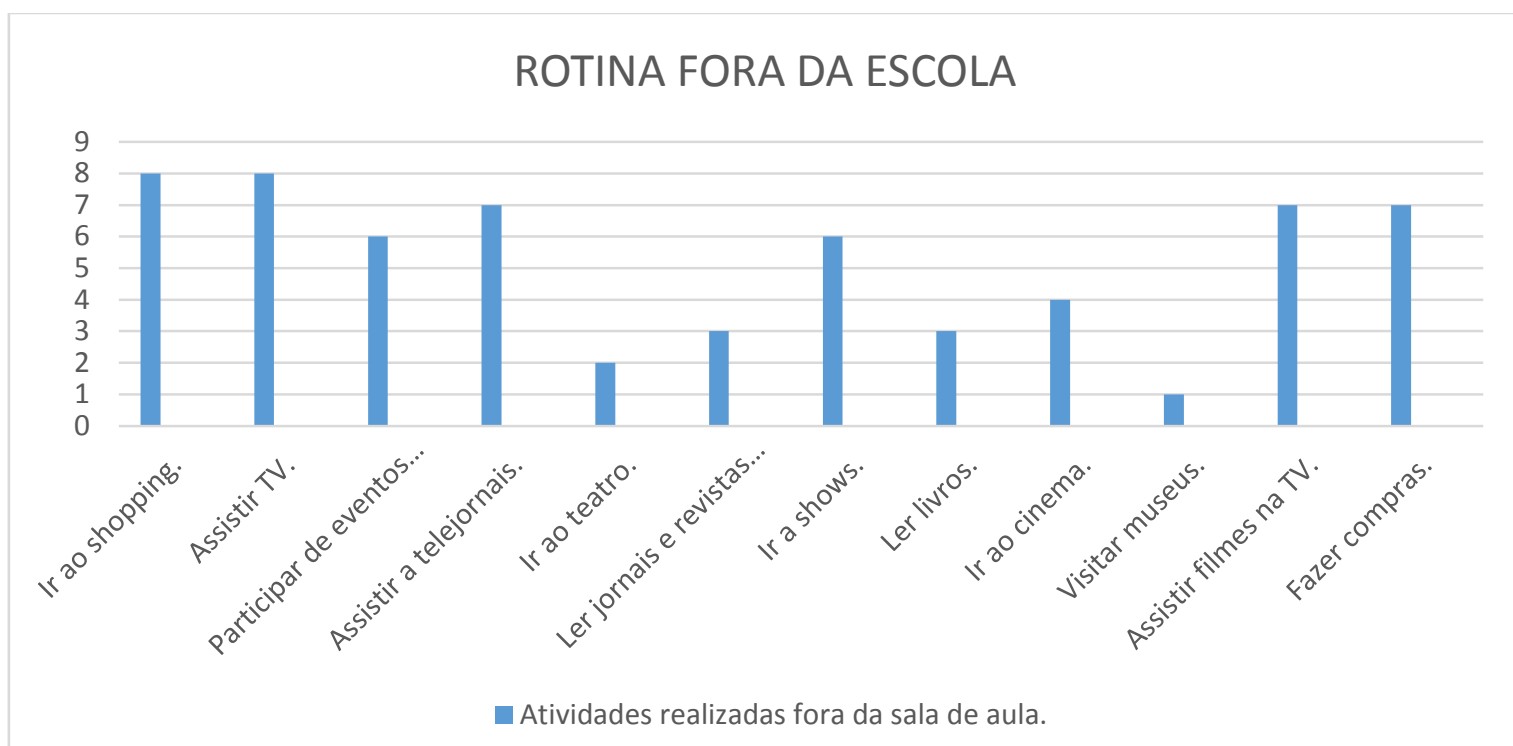

Fonte: Questionário aplicado aos colaboradores (2016) 
Conforme o gráfico 2, mais uma vez, é possível traçarmos o perfil dos colaboradores da pesquisa, através das respostas assinaladas nessa questão. Com o intuito de analisarmos o quanto essas atividades revelam sobre suas rotinas, listamos diferentes situações. Por exemplo, ir ao shopping foi uma prática social assinalada por quase todos. Apesar da crise econômica por que passa nosso país atualmente, muitos deles afirmaram frequentar o shopping. Atividades, como assistir TV, seja telejornais ou outra programação, como filmes, também faz parte da rotina de quase todos os entrevistados.

Além disso, muitos revelaram em suas respostas, que participam de eventos religiosos e que vão a shows. Por outro lado, somente uma pequena parte desses colaboradores afirmou que vai ao teatro, que lê livros, jornais e revistas, que vai ao cinema e a museus. Com isso, depreendemos que, mesmo estando inseridos numa cultura letrada, eles ainda vivem à margem dela, porque essa participação não é efetiva. Não há a participação plena enquanto cidadãos em todos os setores artísticos e culturais, dado visível quando eles afirmam não frequentarem o teatro, cinema e museus.

Dessa forma, embora eles estejam imersos nesse mundo letrado, os alunos dessa modalidade de ensino ainda encontram-se à margem de muitos setores da sociedade. A respeito dessa condição de excluídos da escola, Oliveira (2001) enfatiza o quanto a situação de exclusão contribui para delinear a especificidade dos adultos e jovens como sujeitos de aprendizagem, especialmente quanto aos problemas com a adequação da escola para essa faixa etária que não é "alvo" da instituição. Para ela, os altos índices de evasão e repetência nos programas de EJA indicam uma falta de sintonia entre a escola e os alunos, sem desconsiderarmos outros fatores, como a questão socioeconômica que impede a dedicação plena dos alunos dessa modalidade aos programas.

Jardilino; Araújo (2014, p. 186) corroboram com a autora já citada, afirmando que "Jovens de diferentes condições sociais e culturais, de gêneros e religiões distintas, buscam na educação e com a educação estabelecer um diálogo com a sociedade e com o mercado de trabalho". Esse diálogo pode e deve ser possibilitado pelos demais sujeitos que compõem o espaço escolar, especialmente o professor.

Por isso, o reflexo do sucesso ou insucesso escolar dos alunos da EJA se dá na maneira como eles dialogam com a sociedade em que estão inseridos. A participação desses sujeitos em certos locais, principalmente naqueles ligados à 
cultura, ainda é privilégio de uma minoria. Acerca disso, Lopes (2006) defende que as práticas sociais, envolvendo a leitura e a escrita nos permitem perceber uma possível neutralidade nessas práticas que, na verdade, mascara o real significado da distribuição do poder na sociedade em que se processam por conta do caráter ideológico intrínseco nas relações sociais. Então, compreendemos que as práticas sociais de leitura e escrita retratam o quanto as relações de poder são intrínsecas nas relações sociais.

\section{CONSIDERAÇÕES FINAIS}

Com o intuito de alcançarmos o objetivo pretendido, a saber: analisar como as atividades propostas em sala de aula de uma turma de $8^{\circ}$ ano do Ensino Fundamental, na modalidade EJA relacionam-se ao universo dos alunos fora da escola, buscamos nos aproximar, por meio de pesquisa de campo e da aplicação de um questionário, de algumas das principais situações em que os sujeitos mais utilizam a leitura e a escrita no seu cotidiano.

A partir dos dados coletados, entendemos o quanto a leitura e a escrita estão intrinsecamente ligadas à vida dos colaboradores da pesquisa, desde às atividades mais corriqueiras, como pegar ônibus; até àquelas pouco vivenciadas, como redigir uma carta. Constatamos então, que o aprendizado dessas práticas, apesar dos usos limitados da escrita nas práticas de letramento, representa um resgate da identidade dos alunos pesquisados, fazendo com que a autoestima deles se eleve e que possam conseguir uma integração efetiva nas práticas de letramento do lugar onde vivem. Assim, compreendemos que uma inserção plena nas práticas de letramento exercidas na sociedade, provém de uma estrita relação com as práticas escolares de leitura e de escrita.

Portanto, entendendo que o número de pesquisas no contexto da EJA ainda é pouco satisfatório, esperamos que este trabalho possa contribuir para estudos futuros acerca das práticas de leitura e de escrita nessa modalidade, colaborando, assim, para as reflexões de professores e da gestão escolar, acerca das concepções de leitura e de escrita. E, com isso, tornando viável uma ressignificação da ação docente em sala de aula e proporcionando aos alunos dessa modalidade de ensino, a participação efetiva em práticas sociais de letramento. 


\section{REFERÊNCIAS}

ANTUNES, Irandé. Aula de português: encontro e interação. São Paulo: Parábola, 2003.

FERRAREZI JÚNIOR, Celso. Pedagogia do silenciamento: a escola brasileira e o ensino de língua materna. São Paulo: Parábola, 2014.

FERREIRO, Emília. Reflexões sobre alfabetização. 26. ed. São Paulo: Cortez, 2011.

FREIRE, Paulo. A importância do ato de ler: em três artigos que se completam. 3. ed. São Paulo: Cortez, 1995.

JARDILINO, José Rubens Lima; ARAÚJO, Regina Magna Bonifácio de. Educação de Jovens e Adultos: sujeitos, saberes e práticas. São Paulo: Cortez, 2014.

KLEIMAN, Ângela B. Modelos de letramento e as práticas de alfabetização na escola. In: KLEIMAN, Ângela B. (Org.). Os significados do letramento: uma nova perspectiva sobre a prática social da escrita. Campinas: Mercado das Letras, 1995. p. 15-61.

LOPES, Iveuta de Abreu. Cenas de letramentos sociais. Programa de PósGraduação em Letras da UFPE. Recife: UFPE, 2006.

LIMA, Francisco Renato. Letramentos em contextos de consulta médica: um estudo sobre a compreensão na relação médico-paciente. 2016. 254 f. Dissertação (Mestrado em Letras - Estudos da Linguagem) - Centro de Ciências Humanas e Letras. Universidade Federal do Piauí, Teresina, 2016.

MAGALHÃES NETO, Pedro Rodrigues. Eventos de letramento em situação carcerária. 2013. 218 f. Tese (Doutorado em Letras) - Programa de Pós-Graduação em Letras. Universidade Federal de Pernambuco, Recife, 2013.

OLIVEIRA, Marta Kohl de. Jovens e adultos como sujeitos de conhecimento e aprendizagem. In: RIBEIRO, Vera Masagão (Org.). Educação de jovens e adultos: novos leitores, novas leituras. Campinas: Mercado de Letras, 2001. p. 15-43.

SANTOS, Aliny Cardoso dos. Práticas de letramento e ensino de Língua Portuguesa em contexto de EJA: um estudo em escola pública de Teresina-PI. 2016. 118 f. Dissertação (Mestrado em Letras - Estudos da Linguagem) - Centro de Ciências Humanas e Letras. Universidade Federal do Piauí, Teresina, 2016.

SOARES, Magda. Letramento: um tema em três gêneros. 2. ed. Belo Horizonte: Autêntica, 2010.

STREET, Brian V. Literacy in theory and pratice. Cambridge: Cambridge University Press, 1984. 
Cross-cultural approaches to literacy. Cambridge: Cambridge University Press, 1993.

Social literacies: critical approaches to literacy in development, ethnography and education. Harow: Pearson, 1995.

Abordagens alternativas ao letramento e desenvolvimento.

Teleconferência Brasil sobre o letramento, outubro de 2003.

Letramentos sociais: abordagens críticas do letramento no

desenvolvimento, na etnografia e na educação. Trad. Marcos Bagno. São Paulo:

Parábola, 2014. 